\title{
The breeding system and population structure of the termite Reticulitermes grassei in Southwestern France
}

\author{
CJ DeHeer ${ }^{1}$, M Kutnik ${ }^{2}$, EL Vargo ${ }^{1}$ and A-G Bagnères ${ }^{2}$ \\ ${ }^{1}$ Department of Entomology, North Carolina State University, Box 7613 Gardner Hall, Raleigh, NC 27695, USA; ${ }^{2}$ Institut de Recherche \\ sur la Biologie de l'Insecte, UMR CNRS 6035, Faculté des Sciences et Techniques, Université François Rabelais, Tours 37200, France
}

\begin{abstract}
We assessed colony and population structure in three French populations of the termite Reticulitermes grassei using eight polymorphic microsatellite loci. Although most colonies contained the offspring of multiple, highly related replacement reproductives (complex families), some contained the offspring of a single pair of reproductives (simple families), and the proportion of such colonies varied across populations. Populations also showed variability in the numbers of reproductives within complex families; the $F$ statistics of these families in one population were consistent with having upwards of 100 replacement reproductives, while in another population these colonies contained fewer than 10 pairs of reproductives. Colony boundaries in all populations
\end{abstract}

were well defined, in spite of reports of a widespread breakdown in nestmate recognition and unicolonial populations of $R$. grassei from these regions in France. A second unexpected finding was a lack of significant isolation by distance among colonies within populations, indicating that colony reproduction by budding was rare or absent. The lack of this form of colony reproduction even within populations where it is expected to be common suggested that the propensity for colony budding may not be as common as suggested by the literature.

Heredity (2005) 95, 408-415. doi:10.1038/sj.hdy.6800744; published online 24 August 2005

Keywords: isoptera; breeding system; genetic structure; microsatellites; inbreeding

\section{Introduction}

Detailed knowledge of the genetic structure of populations can yield significant insights into a suite of ecological and evolutionary processes (reviewed in Neigel, 1997; Bossart and Prowell, 1998). For social organisms, genetic structure assumes additional significance not only for the evolution of social behaviour, but also for the evolution of multiple-queen societies, reproductive skew, sex ratio conflict, conflict over growth versus reproduction, and worker reproduction (reviewed in Pamilo et al, 1997; Ross, 2001; Sundström and Boomsma, 2001; Mehdiabadi et al, 2003).

The Hymenoptera, because of their haplodiploid sex determination, formed the bulwark of both Hamilton's (1964) original treatise on kin selection and Trivers and Hare's (1976) seminal work on sex ratio conflict. Therefore, this group has naturally been the focus of most empirical genetic studies on eusocial insect societies (Crozier and Pamilo, 1996). Colony genetic structure in the Hymenoptera exhibits considerably more variation than anticipated (Ross, 2001), and explaining this variation has remained a fundamental goal in the study of these systems (Keller, 1995; Schmid-Hempel and Crozier, 1999; Brown and Schmid-Hempel, 2003). Studies

Correspondence: CJ DeHeer, Department of Entomology, North Carolina State University, Box 7613 Gardner Hall, Raleigh, NC 27695, USA. E-mail:Chris_Deheer@ncsu.edu

Received 17 September 2004; accepted 29 July 2005; published online 24 August 2005 of genetic structure in the eusocial termites should provide an important foil to much of this work, yet the group has received comparatively little genetic scrutiny. Those studies which have been published confirm some of the expectations of termite colony genetic structure, but also raise new questions. In contrast to the Hymenoptera where supernumerary queens tend to outbreed (Keller, 1995; Ross, 2001), termite colonies headed by multiple same-sex reproductives usually exhibit equal or higher nestmate relatedness to colonies with a single pair of breeders, presumably because new reproductives of both sexes are typically recruited from the offspring of the original king and queen (Reilly, 1987; Luykx, 1993; Bulmer and Traniello, 2002b). However, there are sporadic reports of termite colonies with unexpectedly low nestmate relatedness (Clément, 1981; Jenkins et al, 1999; Goodisman and Crozier, 2002; Bulmer and Traniello, 2002b; DeHeer and Vargo, 2004; Dronnet et al, 2005), and several authors suggested that these have resulted from a breakdown in nestmate recognition. Although relatedness within these colonies is generally still much higher than zero, they still provide an interesting parallel to the existence of highly polygynous 'supercolonies' seen in some ant species, which in some cases have been shown to result from a collapse in recognition ability (Morel et al, 1990; Holway et al, 1998; Giraud et al, 2002; Tsutsui et al, 2003).

The western European termite Reticulitermes grassei (=R. lucifugus grassei; Clément et al, 2001) is one such species in which both behavioural (Clément, 1986) and genetic data (Clément, 1981) suggested that colonies 
within some geographic regions lack effective nestmate recognition. Work by Clément and colleagues documented geographic variation in several basic elements of colony genetic structure which correlated with variation in the strength of aggression among colonies (Clément, 1981, 1986; Clément and Bagnères, 1998), and in some regions they have been hypothesized to form expansive 'supercolonies' like some invasive ant species (Clément et al, 2001). Herein we revisit the colony genetic structure of $R$. grassei, armed with microsatellite markers (Vargo, 2000; Dronnet et al, 2004), formal genetic analyses (Weir and Cockerham, 1984; Queller and Goodnight, 1989), and recent simulation models of breeding systems developed specifically for the Isoptera (Thorne et al, 1999). Our objective was to obtain a detailed picture of the breeding system of $R$. grassei from several separated populations in southwest France, with specific goals of characterizing geographic variation in breeding system and determining the nature of colony boundaries in these locations. These data allowed us to obtain relevent information on higher level genetic structure among populations of this termite, and also potentially gain insights into mechanisms of new colony propagation and the dispersal potential of winged reproductives. We do note that the taxonomic status of Reticulitermes is still in flux (eg, Austin et al, 2002), and that $R$. grassei was recently elevated to species status (reviewed in Clément et al, 2001). The current work on colony and population genetic structure should thus complement the growing body of work on the life history, systematics, and phylogeography of Reticulitermes in Europe (Uva et al, 2004; Kutnik et al, 2004, in preparation).

\section{Methods}

\section{Field collections}

During June of 2003 we collected termites from three spatially separated populations (A, B, and C) in southwest France (Figure 1). Population A was located about $5 \mathrm{~km}$ west of La Tremblade in La Coubre Forest (In the département of Charente Maritime), Population B was located about $5 \mathrm{~km}$ west of Ychoux (Landes), and population $\mathrm{C}$ was located about $5 \mathrm{~km}$ east of Pissos (Landes). These populations were separated from one another by between 35 and $170 \mathrm{~km}$. Although these populations were somewhat haphazardly distributed across this region, these particular locations had the advantage of having known established termite populations from which we were permitted to collect, and from which preliminary data on genetic structure had been obtained previously (Clément et al, 2001; Kutnik et al, 2004). Each of these locations consisted of a managed forest, although habitat still varied widely across these populations. Population A was more heavily managed than the other populations and was a relatively open forest with widely spaced mature pines. Population B was a clear cut containing the stumps of mature harvested pines that was bordered by mature forest on all sides. Population C was a young (20-30 years old) stand of closed canopy pine forest in close proximity to several cultivated fields. Within each population, we collected from multiple, spatially separated feeding sites (usually tree stumps), and from each feeding site we obtained at least 40 workers. Although we attempted to

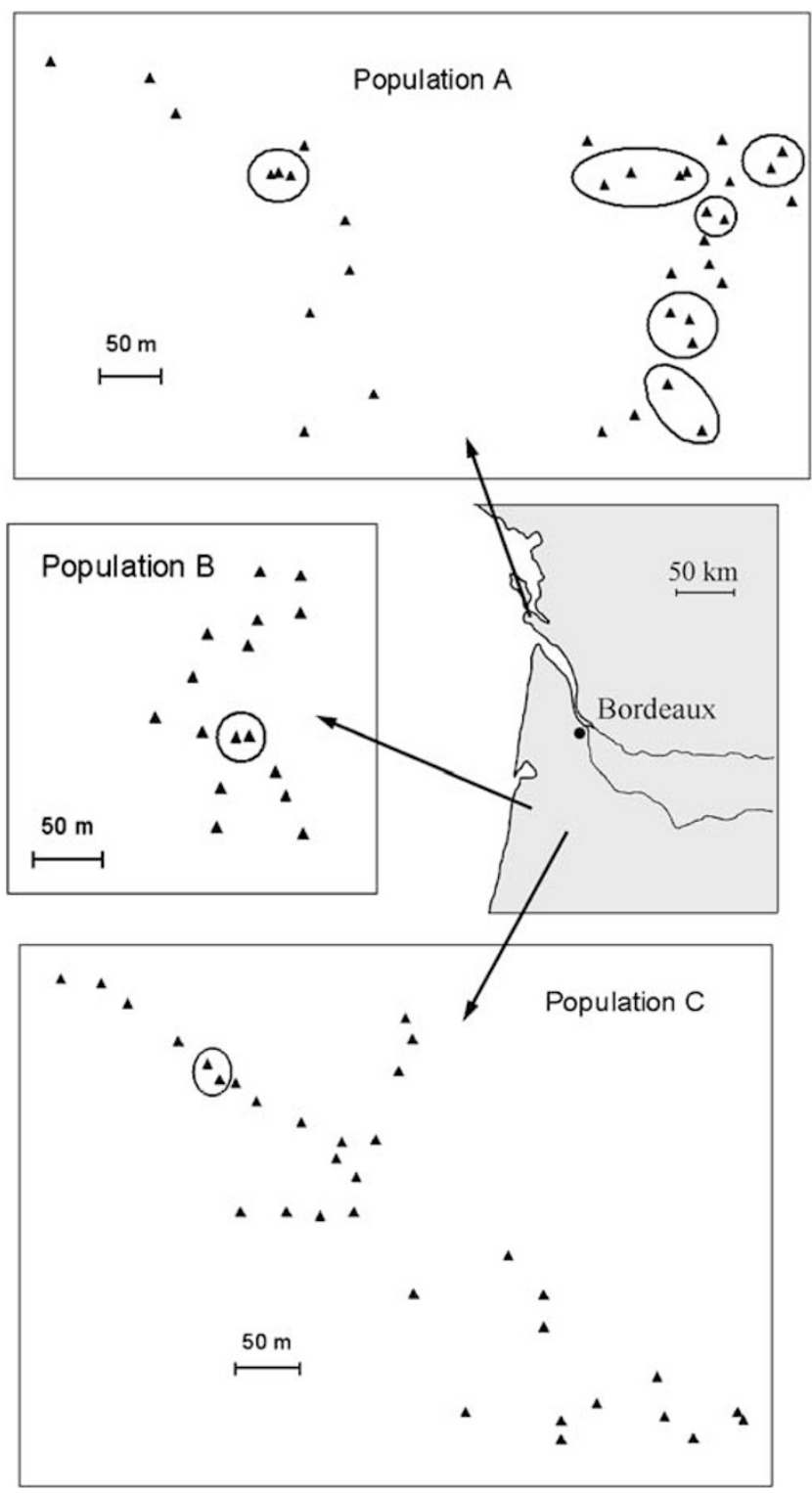

Figure 1 The spatial distribution of collections of R. grassei from three populations in southwestern France. Circles surround those collection points, which contained workers belonging to the same colony.

make these collections along a straight line transect, the extreme patchiness of termite feeding locations prevented us from entirely relying upon this more systematic collection method. In order to maximize the numbers of different colonies from which we collected, we typically collected only from those feeding sites which were separated from other such collection points by at least $15 \mathrm{~m}$. In the field we preserved 20-100 termites from each colony in $95 \%$ ethanol, and immersed an additional 20 termites in $4 \mathrm{ml}$ of pentane. The former were used for genetic analyses, while the pentane extracts were analysed for their cuticular hydrocarbon profiles. In both cases the samples were stored in the laboratory for approximately 3 months at $4{ }^{\circ} \mathrm{C}$ until the respective analyses could be performed. We mapped the feeding sites at which we collected termites by measuring the linear distance between consecutively collected locations as well as their angular deviation relative to the magnetic north pole. 
Genetic data collection

We isolated DNA from the whole bodies of 20-40 worker termites from each feeding site using the Puregene $^{\mathrm{TM}}$ DNA isolation kit (Gentra Systems, Inc., Minneapolis, MN, USA), and resuspended the dried pellet in $300 \mu \mathrm{l}$ of $1 \times \mathrm{TE}$ buffer. We determined the genotypes of these termites $(n=1940)$ at eight polymorphic microsatellite loci. (Rf6-1, Rf15-2, Rf21-1, and Rf24-2 from Vargo, 2000; Rs62, Rs76, and Rs78 from Dronnet et al, 2004). The eighth locus, Rs1 (F 5'-atctctcaagcgaaagtggc- $3^{\prime}$, $\mathrm{R} 5^{\prime}$-cgttggagcaacagggac- $3^{\prime}$ ), is a trimeric repeat (GTT) developed for $R$. santonensis simultaneously to those reported in Dronnet et al (2004).

Primers $R f 21-1, R f 24-2$, and Rs78 were amplified in a single reaction following the conditions of Vargo (2000), except that the final primer concentrations were $150 \mu \mathrm{M}$ for $R f 21-1$ and $40 \mu \mathrm{M}$ for both $R f 24-2$ and Rs78. The remaining loci were amplified in two multiplexed reactions ( $R f 6-1$ with $R f 15-2$ and $R s 1$; Rs62 with $R s 76$ ), and both reactions followed Vargo (2000) except for two modifications. The annealing temperature was increased to $57^{\circ} \mathrm{C}$ in order to eliminate the occurrence of nonsense bands which interfered with scoring, and the primer concentrations were modified in order to equalize the amplification strength of the various loci ( $R f 6-1$ and $R s 76$ : $40 \mu \mathrm{M}$, Rs62: $50 \mu \mathrm{M}$, Rs1: $60 \mu \mathrm{M}$, Rf15-2: $130 \mu \mathrm{M})$. PCR products were separated by electrophoresis on $6 \%$ polyacrylamide gels run on a Li-Cor 4300 DNA analyzer, and allele sizes determined by comparison to $50-350 \mathrm{bp}$ IRDye700 ${ }^{\mathrm{TM}}$ or 800 standard (Li-Cor, Inc.).

\section{Data analysis}

We first determined the boundaries of colonies within each population by estimating genotypic differentiation between all pairs of feeding sites using Genepop on the web (Raymond and Rousset, 1996). Genepop assessed the significance of differentiation at each locus with a log-likelihood $(G)$-based exact test, and the overall significance was determined via Fisher's combined probability test. Feeding sites were considered part of different colonies when differentiation between them was significant.

We next obtained estimates of genotypic disequilibrium using Fstat 2.9.3.2 (Goudet, 2001). In order to circumvent possible problems that may arise from the nonindependence of genotypes within colonies, we performed this analysis on 20 resampled datasets, each of which consisted of a single worker randomly drawn from each colony. The overall significance of disequilibrium for each pair of loci within each population was assessed by averaging the $P$-values across all 20 resampled datasets. We also obtained estimates of allele frequencies for each locus using Fstat on these resampled datasets (again, to avoid the problem of nonindependence of genotypes from the same colony), for which we report the average frequency over all data subsets.

We classified colonies into either simple families or complex families, based on their genotype distributions at all eight loci. We defined simple families as those in which the worker genotype distributions did not differ from those expected for a single pair of reproductives. Significant deviation was assessed at each locus with a G-test, and overall significance was determined using Fisher's combined probability test. We defined complex families as those in which either (1) the workers collectively had too many genotypes at any one locus $(>4)$ to have a single pair of parents, or (2) the genotype distributions differed significantly from those expected from a single pair of reproductives (as above). Previously we have subdivided complex families into extendedfamily colonies (those having multiple reproductives which are the descendants of the original founding pair) and mixed-family colonies (those having three or more unrelated reproductives) (DeHeer and Vargo, 2004). However, insufficient marker variability prevented us from differentiating between these two family structures for individual colonies, and we therefore analysed them together here.

We estimated colony level F-statistics (Weir and Cockerham, 1984) and nestmate relatedness (Queller and Goodnight, 1989) separately in each population with Fstat 2.9.3.2. Within each population we also estimated these F-statistics separately for the simple- and complexfamily colonies. Confidence intervals (CI) were generated by bootstrapping over loci, and these results were compared to different models of termite-breeding structure proposed by Thorne et al (1999) and Bulmer et al (2001). Empirical estimates were considered significantly different from one of the modelled breeding systems when their CI did not overlap the model estimate for at least one of the parameters $\left(F_{\mathrm{IC}}, F_{\mathrm{IT}}, F_{\mathrm{CT}}\right.$, or $\left.r\right)$. We followed Thorne et al (1999), for the notation and biological interpretation of the $F$-statistic parameters: $F_{\text {IC }}$ is the inbreeding of individuals relative to the colony level, $F_{\mathrm{IT}}$ is the inbreeding of individuals relative to the population (and since this is computed independently in each population, this is equivalent to true inbreeding $F_{\text {IS }}$ ), while $F_{\text {CT }}$ represents differentiation among colonies within each population. Statistical differences between $F$ statistic and relatedness point estimates were determined using the permutation method available in Fstat 2.9.3.2.

We determined the likelihood for colony reproduction by budding in each population by assessing isolation by distance among colonies. This was done by examining the correlation between pairwise differentiation $\left(F_{\mathrm{CT}}\right)$ and the linear distance separating colonies. The significance of this correlation was determined via Mantel tests using the program Fstat. Additionally, we followed the lead of other studies (Bulmer and Traniello, 2002a; DeHeer and Vargo, 2004) by exploring the relationship between colony size and $F_{\text {IC. }}$ This colony level inbreeding coefficient is particularly sensitive to the number and distribution of reproductives within colonies: it is strongly negative when there are few reproductives, it approaches zero as the numbers of reproductives increases, but can be considerably greater than zero when a colony contains multiple, independent centres of reproduction (particularly as a result of the mixing of workers between unrelated colonies). If colonies that are more expansive, in fact, do have more reproductives than smaller colonies, we anticipated finding a positive correlation between colony-foraging range and $F_{\text {IC. }}$.

We examined possible differentiation among populations by assessing hierarchical genetic structure (Weir, 1996) with the program GDA 1.1 (Lewis and Zaykin, 2001). Significance was determined by bootstrapping over loci, and with this program we also obtained pairwise estimates of differentiation among the three populations. 


\section{Results}

Collections and identification of samples

We collected termites from 84 different feeding sites spread across all three populations (35, 16, and 33 feeding sites from populations A, B, and C, respectively; see Figure 1). These populations were located in an area where $R$. grassei and R. santonensis can sometimes occur in sympatry. Nevertheless, the cuticular hydrocarbon profiles of all samples matched the profiles of $R$. grassei from previous reports (Bagnères et al, 1991; Clément et al, 2001; Kutnik et al, 2004), indicating that this was the only species we obtained in our collections.

\section{Genetic markers}

In Table 1 we show the numbers of alleles and the overall expected heterozygosity for the eight loci used in this study. None of the loci showed consistent patterns of genotypic disequilibrium within the three populations used in this study. Out of 4620 possible comparisons for disequilibrium (we tested disequilibrium on each of 20 different datasets consisting of a single worker drawn from each colony), only 67 (1.5\%) showed significant departures from equilibrium. Moreover, these appeared to be randomly distributed across possible pairs of loci: the average significance of disequilibrium for any one pair of loci across all 20 datasets was never lower than 0.30 .

\section{Colony boundaries}

We grouped several sets of feeding sites into the same colony, based upon the exact tests of genotypic differentiation. In populations $B$ and $C$ this was very straightforward: only a single pair of adjacent feeding sites in each population showed no significant differentiation (see Figure 1), while every other pair of sites showed highly significant differentiation $(P<0.0001)$ at two or more loci. The northernmost population (A), on the other hand, showed several ambiguous cases of feeding site differentiation. These arose when delimiting the boundaries of three multisite colonies in population A. One feeding site within these groups of sites was not significantly differentiated from either a second or a third feeding site, but these latter two sites showed slight but significant differentiation from one another at one or two loci. In these cases, we concluded that all three sites were part of a single, spatially structured colony; this would not be unexpected given the complex family structure

Table 1 Number of alleles (Na) and the overall expected heterozygosity (He) for the microsatellite loci used in this study

\begin{tabular}{llc}
\hline Locus & $\mathrm{Na}$ & $\mathrm{He}$ \\
\hline Rf6-1 & 4 & 0.26 \\
Rf15-2 & 2 & 0.48 \\
Rf21-1 & 7 & 0.69 \\
Rf24-2 & 2 & 0.48 \\
Rs1 & 3 & 0.62 \\
Rs62 & 2 & 0.50 \\
Rs76 & 2 & 0.38 \\
Rs78 & 2 & 0.46 \\
Average & & \\
\hline
\end{tabular}

(see below) and the large distances over which colonies seemed to forage in this population.

There appeared to be a general difference in the proportion of spatially expansive colonies between the northern population (A) and those further south (B and C; see Table 2). Population A had a greater proportion of colonies occupying multiple feeding sites (seven out of 24 colonies) than did population $\mathrm{C}$ (one out of 32 colonies; Fisher's exact test, two-tailed; $P=0.016)$ or the two southern populations ( $B$ and $C$ ) combined (two out of 47 colonies; Fisher's exact test, two-tailed; $P=0.006$ ). Populations A and B (one out of 15 colonies), however, did not differ significantly from one another in the proportion of multisite colonies (Fisher's exact test, two-tailed; $P=0.121$ ).

\section{Breeding system and genetic structure}

A preliminary analysis indicated that utilizing 20 workers per colony did not provide sufficient statistical power to discriminate simple families from complex families in all cases. Specifically, when the workers in a colony collectively have no more than two alleles at any locus, the expected genotype ratios for the offspring of large numbers of replacement reproductives may be indistinguishable from the expected genotype ratios for a simple family in which both parents are heterozygous at the biallelic loci. Therefore, for colonies with no more than two alleles at any one locus, we genotyped a minimum of 40 workers at all eight loci.

In Table 2 we show the breakdown of colonies into simple and complex families for each site. The sampled colonies in site A did not contain any simple families, and this proportion was significantly lower than the proportion of simple families found either at site B (Fisher's exact test, two-tailed; $P=0.015$ ) or at site $\mathrm{C}$ (Fisher's exact test, two-tailed; $P<0.0001$ ). Although sites $B$ and $C$ exhibited a slight difference in the proportion of simple families, this was not statistically significant (Fisher's exact test, two-tailed; $P=0.343$ ).

We failed to detect a strong association between colony-foraging area and colony family structure. None of the simple families $(n=18)$ occupied more than one of the sampled feeding sites, compared to $17 \%$ (nine of 53) of the complex family colonies (Fisher's exact test, onetailed, 0.060). Considering only the complex family colonies, the $F_{\mathrm{IC}}$ values for colonies feeding at multiple sampling locations (median 0.015) was not significantly

Table 2 The numbers of colonies collected in each population, broken down by family structure and whether or not workers were collected from multiple feeding sites

\begin{tabular}{lcc}
\hline & Single-site colonies & Multiple-site colonies \\
\hline Population A & 0 & 0 \\
$\quad$ Simple families & 17 & 7 \\
$\quad$ Complex families & & \\
Population B & 4 & 0 \\
$\quad$ Simple families & 10 & 1 \\
Complex families & & \\
& & 0 \\
Population C & 14 & 1 \\
$\quad$ Simple families & 17 & \\
$\quad$ Complex families & & \\
\hline
\end{tabular}


Table 3 Observed (with 95\% CI) and expected colony level F-statistics and nestmate relatedness ( $r$ ) broken down by population and by family structure

\begin{tabular}{|c|c|c|c|c|}
\hline Breeding system & $\mathrm{F}_{I C}$ & $\mathrm{~F}_{I T}$ & $\mathrm{~F}_{C T}$ & $r$ \\
\hline \multicolumn{5}{|l|}{ Observed } \\
\hline Pop. A - Complex families $(N=24)$ & $0.019(-0.016$ to 0.054$)$ & $0.294(0.180-0.408)$ & $0.280(0.183-0.377)$ & $0.435(0.321-0.549)$ \\
\hline Pop. B - Simple families $(N=4)$ & $-0.212(-0.335$ to -0.065$)$ & $0.330(0.068-0.545)$ & $0.450(0.214-0.632)$ & $0.688(0.393-0.826)$ \\
\hline Pop. B - Complex families $(N=11)$ & $-0.038(-0.115$ to 0.036$)$ & $0.297(0.191-0.375)$ & $0.322(0.262-0.369)$ & $0.498(0.434-0.544)$ \\
\hline Pop. C - Simple families $(N=14)$ & $-0.250(-0.302$ to -0.191$)$ & $0.080(0.027-0.136)$ & $0.264(0.225-0.292)$ & $0.490(0.431-0.529)$ \\
\hline Pop. C - Complex families $(N=18)$ & $-0.113(-0.167$ to -0.042$)$ & $0.312(0.238-0.394)$ & $0.381(0.326-0.441)$ & $0.582(0.519-0.638)$ \\
\hline \multicolumn{5}{|l|}{ Expected } \\
\hline a. Primaries, unrelated & -0.34 & 0.00 & 0.25 & 0.50 \\
\hline b. Replacements, $n=1, \mathrm{X}=1$ & -0.14 & 0.33 & 0.42 & 0.62 \\
\hline c. Replacements, $n=1, X=3$ & -0.22 & 0.57 & 0.65 & 0.82 \\
\hline d. Replacements, $n=10, X=3$ & -0.02 & 0.37 & 0.38 & 0.56 \\
\hline e. Replacements, $n=100, X=3$ & -0.00 & 0.34 & 0.34 & 0.51 \\
\hline $\begin{array}{l}\text { f. Replacements, } n=10, X=3 \text {, } \\
\text { cooperatively founded by } 3 \text { alates }\end{array}$ & -0.03 & 0.27 & 0.29 & 0.45 \\
\hline $\begin{array}{l}\text { g. Mixing between related colonies, } \\
n=1, X=3, P=0.90\end{array}$ & 0.04 & 0.66 & 0.64 & 0.77 \\
\hline $\begin{array}{l}\text { h. Mixing between unrelated colonies, } \\
n=10, X=3, P=0.80\end{array}$ & 0.15 & 0.37 & 0.25 & 0.36 \\
\hline
\end{tabular}

For the simulated breeding systems, $n$ represents the number of pairs of reproductives, $X$ is the number of generations of inbreeding among replacement reproductives, and $p$ represents the proportion of worker mixing between different colonies which have connected tunnel systems.

Table 4 Summary of the breeding systems predominating within each population

\begin{tabular}{lrlllc}
\hline & \multicolumn{2}{c}{ Simple families } & & \multicolumn{2}{c}{ Extended families } \\
\cline { 2 - 3 } \cline { 5 - 6 } & $\%$ & Inbred & & \# Reproductives \\
\hline Population A & 0 & & & 100 & $100 \mathrm{~s}$ \\
Population B & 27 & Yes, $\sim 1$ generation & & 73 & $10 \mathrm{~s}-100 \mathrm{~s}$ \\
Population C & 44 & Sometimes & & 56 & $<10$ \\
\hline
\end{tabular}

higher than those for complex families collected at only one sampling location (median -0.024) (Kruskal-Wallis test; $P=0.066$ ).

We give details on the observed and expected (case $\mathrm{a}-\mathrm{h}$ ) colony level $\mathrm{F}$-statistics and nestmate relatedness in Table 3, and we summarize these results in Table 4. Complex families in population A exhibited F-statistics consistent with those expected for colonies having large numbers of replacement reproductives (case e), and differed significantly (based on their 95\% CI) from all other breeding systems in at least one of the four genetic parameters $\left(F_{\mathrm{IC}}, F_{\mathrm{IT}}, F_{\mathrm{CT}}\right.$, and/or $\left.r\right)$. Using the same criteria, the complex families in population $\mathrm{B}$ differed significantly from all the breeding systems except two (cases e and f), and thus are likely to be headed by large numbers of replacement reproductives (tens to hundreds). In contrast, the genetic parameters for the complex families in population $C$ were suggestive of smaller numbers of reproductives (case $b$ ); the average $F$-statistics therein differed significantly in at least one parameter from every other modelled breeding system. Moreover, when directly compared to population A, complex families in population $\mathrm{C}$ exhibited significantly more negative $F_{\mathrm{IC}}(P=0.012)$, and significantly higher $F_{\mathrm{CT}}$ and $r(P=0.012$ and 0.0001 , respectively $)$, both of which are expected for colonies with fewer reproductives.
The simple families in population B, although few in number, exhibited average $F$-statistics consistent with having a single pair of related reproductives (case b). In spite of their substantial levels of inbreeding $\left(F_{\mathrm{IT}}=0.33\right)$ not all these simple families were necessarily headed by a pair of replacement reproductives, because in one of these colonies we collected a pair of colony-founding primary reproductives. The simple families in population $C$ did not have $F$-statistics consistent with any one breeding system; this situation is likely to arise when colonies are represented by a mixture of breeding systems, with no single type of colony predominating.

We detected no significant correlation between geographic distance and genetic differentiation among colonies within any of the three populations. Population $B$ showed the strongest trend for isolation by distance but even here, the proportion of explained variation was low and only marginally significant $\left(R^{2}=3.2, P=0.07\right)$. Thus, colonies were no more likely to be related to their neighbours than to more distant colonies, at least over the scale of several hundred meters.

Higher-level structure at the scale of many $\mathrm{km}$, however, was significant. Among-population $F_{\mathrm{ST}}$ was 0.105 and significantly greater than zero (95\% CI: $0.061-$ 0.140). Most of this among-population differentiation appeared to be due to differences between population $\mathrm{A}$ and the two southern populations. Pairwise measures of $F_{\mathrm{ST}}$ were significant between $\mathrm{A}$ and $\mathrm{B}$ and between $A$ and $C$ (0.137 and 0.139 , respectively), but negligible between populations B and C $(-0.008)$.

\section{Discussion}

We found extensive within- and among-population variation in colony genetic structure among these populations of $R$. grassei (summarized in Table 4). One source of variation was that populations differed in the proportion of colonies with a single pair of reproductives versus those with more than a single king and queen. 
Colonies in population A were all complex families, while both populations B and C had a significantly greater proportion of simple family colonies (26.6 and $43.8 \%$, respectively). A second source of variation arose from differences among populations in the numbers of reproductives within the complex family colonies. In populations A and B these colonies exhibited $F$-statistics consistent with having tens or hundreds of pairs of replacement reproductives, whereas those in population $\mathrm{C}$ appeared to contain far fewer (more than one pair but fewer than 10 pairs).

Simple-family colonies in both populations in which they occurred were significantly inbred. In population $B$ the inbreeding coefficient $\left(F_{\mathrm{IT}}\right)$ was consistent with these colonies being headed by either first-generation replacement reproductives or by primary reproductives which were close relatives. However, the $F_{\mathrm{IT}}$ of simple-family colonies in population $\mathrm{C}$ was lower than expected for closely related pairs of reproductives, while still being significantly inbred. This intermediate level of inbreeding for the latter population suggests that these simplefamily colonies were a mixture of colonies whose workers were the offspring of either unrelated or related reproductive pairs.

The simultaneous occurrence of both simple and complex families in one population is not particularly remarkable. This was expected from their life history (Roisin, 1993; Thorne et al, 1999), has already been shown across regional scales in this species (Clément, 1981), and has been described in several other termite species (Thompson and Hebert, 1998; Bulmer et al, 2001; Goodisman and Crozier, 2002; Vargo, 2003a; DeHeer and Vargo, 2004). The underlying causes of this variation remain unclear. In the case of the current study, it may be that the differences in habitat across populations could affect the breeding system of termite colonies, for example by altering the age structure of colonies within populations. The fact that the youngest forest also contained colonies with fewer replacement reproductives than other populations might suggest that there is a correlation between colony age (or size) and forest age (or food abundance), but without greater numbers of populations we cannot formally test this association. We do note, however, that such interpopulation variability in family structure is not a universal feature in termites, as some studies have documented very little variation across broad geographic scales (Dronnet et al, 2005).

Nevertheless, in spite of some similarities, the current study differs markedly from some previous work in its assessment of patterns of colony reproduction in subterranean termites. The ability of subterranean termites like Reticulitermes to generate replacement reproductives with relative ease has often been cited as a characteristic conducive to colony reproduction by budding, whereby workers and replacement reproductives initiate new colonies in close proximity to their natal nest (Myles and Nutting, 1988; Thorne et al, 1999). However, we found no evidence for genetic isolation by distance among colonies within populations, and therefore conclude that colony reproduction by budding was relatively rare in the populations that we studied. Previous work on $R$. flavipes has also failed to find this footprint of colony budding (Vargo, 2003b; DeHeer and Vargo, 2004), but this could be because populations of this latter species are populated by colonies initiated by primary reproductives, which initiate colonies after dispersal flights. The same caveat, however, cannot be made for the current results in $R$. grassei.

Lastly, we can draw some conclusions regarding the dispersal of colony-founding kings and queens based on the analyses of structure within and among populations. The lack of isolation by distance among colonies suggests that most new colonies are initiated by winged kings and queens during swarms, and that the dispersal of those individuals that successfully initiate new colonies is typically greater than the distance separating colonies. Across larger spatial scales, on the other hand, we did find significant structure. Populations showed significant differentiation from one another $\left(F_{\mathrm{ST}}=0.105\right)$, most of which resulted from differences between the northern population, A, and the two southern populations. Although the genetic and physical distances separating these three populations are suggestive of isolation by distance over large spatial scales (with the greatest differentiation between pairs of populations separated by the greatest distances), we had insufficient numbers of populations to test this rigorously.

We note that the colony genetic structure, which we describe here, is quite different from that described by Clément for $R$. grassei from this region in France (Clément, 1981; reviewed in Clément et al, 2001). First, Clément described the population of $R$. grassei from the pine forest in La Coubre (the same location as our population A) as consisting of mostly (82\%) simplefamily colonies, whereas we found that all the colonies from this forest were extended families. Second, more recent studies by Clément and colleagues (Clément, 1986; Clément et al, 2001) have combined observations on worker aggression and the previous genetic work (Clément, 1981). They hypothesize that colonies in the region south of La Coubre (encompassing our populations B and C) are 'open societies' which exchange both reproductives and workers during the summer months when aggression is on average low, and that this entire region should be considered one extensive supercolony (Clément et al, 2001). In contrast, our results here demonstrate that open societies are at best rare in the populations we have studied: the majority of collection points were strongly differentiated from one another and average nestmate relatedness $(r)$ was not significantly lower than 0.50 .

The differences between the current study and that of Clément $(1981,1986)$ could reflect a genuine change in colony genetic structure that has occurred over the last 25 years. If, for example, the colonization and ageing of termite colonies parallels that of the forest in which they reside, the termite colonies may have grown and replaced their founding kings and queens with numerous secondary reproductives within the last 25 years. Although this hypothesis is at least plausible for population A, which consisted of mostly older forest, it cannot explain the putative reversion within populations $\mathrm{B}$ and $\mathrm{C}$ from unicolonial populations into those consisting of distinct, multiple colonies. Moreover, it is much simpler to argue that the observed differences have resulted because Clément (1981) based most of his conclusions on only two allozyme loci, and also did so without the aid of modern techniques in the analysis of colony genetic structure (eg, Thorne et al, 1999). Even with eight polymorphic microsatellite loci, we could not 
always differentiate between simple and extended families until we had analysed at least 40 workers and, on average, we could differentiate between any two colonies at only three of our eight loci. Lastly, subsequent behavioural work has in fact found a more complicated pattern of among-colony aggression than did Clément (1986), suggesting that these previous conclusions about colony boundaries do not apply to this entire region. Working only a short time after this original work, Bagnères (1989) found three distinct differences: (1) that colonies were generally more aggressive towards one another than reported by Clement (1986), (2) that this aggression exhibited extensive between-colony variation (half of the pairwise interactions were highly aggressive while the other half showed intermediate to low aggression), and (3) that aggression did not vary in a seasonal pattern.

Detailed studies of colony and population structure in the Isoptera should continue to yield important insights into the sociogenetic organization of these societies. We have demonstrated here that the number of reproductives and their relatedness to one another show substantial within- and among-population variability in $R$. grassei. Nevertheless, the high genetic relatedness within colonies indicates that colony boundaries can remain distinct even when nestmate recognition appears weak or variable when assayed in the laboratory (see also Bulmer and Traniello, 2002b; DeHeer and Vargo, 2004). These patterns provide an interesting contrast to the breakdown in nestmate recognition which correlates with the near-zero nestmate relatedness (Ross, 1993) or even unicoloniality seen in some hymenopteran systems (Holway et al, 1998; Giraud et al, 2002). Our lack of support for colony reproduction via budding was also somewhat unexpected, and also contrasts with what has been described in some highly polygynous ant societies (Chapuisat et al, 1997; Pirk et al, 2001; Fournier et al, 2002). This could reflect a greater ongoing connectivity between daughter nests in subterranean termites when compared to polygynous ants, although more studies are clearly needed to assess the generality of this pattern.

\section{Acknowledgements}

We thank Hope Dalton and Ana Vargo for their help making field collections. This work was supported by a travel Grant from CNRS to AGB (\#14574), a NSF travel Grant to ELV (INT-0233238), and USDA-NRICGP Grants to ELV (00-35302-9377 and 2002-35302-12490).

\section{References}

Austin JW, Szalanski AL, Uva P, Bagnères A-G, Kence A (2002). A comparative genetic analysis of the subterranean termite genus Reticulitermes (Isoptera: Rhinotermitidae). Ann Ent Soc Am 95: 753-760.

Bagnères A-G (1989). Les Hydrocarbures Cuticulaires des Insectes Sociaux. Détermination et Rôle dans la Reconnaissance Spécifique Coloniale et Individuelle Thèse de Doctorat de l'Université P. et M. Curie. 250pp.

Bagnères A-G, Killian A, Clément J-L, Lange C (1991). Interspecific recognition among termites of the genus Reticulitermes: evidence for a role for the cuticular hydrocarbons. J Chem Ecol 17: 2397-2420.
Bossart JL, Prowell DP (1998). Genetic estimates of population structure and gene flow: limitations, lessons and new directions. Trends Ecol Evol 13: 202-206.

Brown MJF, Schmid-Hempel P (2003). The evolution of female multiple mating in social Hymenoptera. Evolution 57: 2067-2081.

Bulmer MS, Adams ES, Traniello JFA (2001). Variation in colony structure in the subterranean termite Reticulitermes flavipes. Behav Ecol Sociobiol 49: 236-243.

Bulmer MS, Traniello JFA (2002a). Foraging range expansion and colony genetic organization in the subterranean termite Reticulitermes flavipes (Isoptera: Rhinotermitidae). Environ Entomol 31: 293-298.

Bulmer MS, Traniello JFA (2002b). Lack of aggression and spatial association of colony members in Reticulitermes flavipes. J Ins Behav 15: 121-126.

Chapuisat M, Goudet J, Keller L (1997). Microsatellites reveal high population viscosity and limited dispersal in the ant Formica paralugubris. Evolution 51: 475-482.

Clément J-L (1981). Enzymatic polymorphism in the European populations of various Reticulitermes species (Isoptera). In: Howse PE, Clément J-L (eds) Biosystematics of Social Insects. Academic Press: New York, pp 49-62.

Clément J-L (1986). Open and closed societies in Reticulitermes termites (Isoptera, Rhinotermitidae): geographic and seasonal variations. Sociobiology 11: 311-323.

Clément J-L, Bagnères A-G (1998). Nestmate recognition in termites. In: Vander Meer RK, Breed M, Winston M, Espelie $\mathrm{K}$ (eds) Pheromone Communication in Social Insects: Ants, Wasps, Bees, and Termites, pp 126-155.

Clément J-L, Bagnères A-G, Uva P, Wilfert L, Quintana A, Reinhard J et al (2001). Biosystematics of Reticulitermes termites in Europe: morphological, chemical and molecular data. Insect Soc 48: 202-215.

Crozier RH, Pamilo P (1996). Evolution of Social Insect Colonies. Oxford University Press: New York.

DeHeer CJ, Vargo EL (2004). Colony genetic organization and colony fusion in the termite Reticulitermes flavipes as revealed by foraging patterns over time and space. Mol Ecol 13: 431-441.

Dronnet S, Bagnères A-G, Juba TR, Vargo EL (2004). Polymorphic microsatellite loci in the European subterranean termite, Reticulitermes santonensis Feytaud. Mol Ecol Notes 4: $127-129$.

Dronnet S, Chapuisat M, Vargo EL, Lohou C, Bagnères A-G (2005). Genetic analysis of the breeding system of an invasive subterranean termite, Reticulitermes santonensis, in urban and natural habitats. Mol Ecol 14: 1311-1320.

Fournier D, Aron S, Milinkovitch MC (2002). Investigation of the population genetic structure and mating system in the ant Pheidole pallidula. Mol Ecol 11: 1805-1814.

Giraud T, Pedersen JS, Keller L (2002). Evolution of supercolonies: the Argentine ants of southern Europe. Proc Natl Acad Sci USA 99: 6075-6079.

Goodisman MAD, Crozier RH (2002). Population and colony genetic structure of the primitive termite Mastotermes darwiniensis. Evolution 56: 70-83.

Goudet J (2001). FSTAT, a program to estimate and test gene diversities and fixation indices (version 2.9.3). Available from http://www2.unil.ch/izea/softwares/fstat.html

Hamilton WD (1964). The genetical evolution of social behavior. II. J Theoret Biol 7: 17-52.

Holway DA, Suarez AV, Case TJ (1998). Loss of intraspecific aggression in the success of a widespread invasive social insect. Science 282: 949-952.

Jenkins TM, Basten CJ, Kresovich S, Forschler BT (1999). Mitochondrial gene sequence questions Reticulitermes sp. social structure (Isoptera: Rhinotermitidae). Sociobiology 34: 161-172.

Keller L (1995). Social life: the paradox of multiple-queen colonies. Trends Ecol Evol 10: 355-360. 
Kutnik M, Uva P, Brinkworth L, Bagnères A-G (2004). Phylogeography of two European Reticulitermes (Isoptera) species: the Iberian refugium. Mol Ecol 13: 3099-3113.

Lewis PO, Zaykin D (2001). Genetic Data Analysis: Computer program for the analysis of allelic data. Version 1.1 (d16c). Free program distributed by the authors over the internet from http://hydrodictyon.eeb.uconn.edu/people/plewis/ software.php

Luykx P (1993). Turnover in termite colonies: a genetic study of colonies of Incisitermes schwarzi headed by replacement reproductives. Insect Soc 40: 191-205.

Mehdiabadi NJ, Reeve HK, Mueller UG (2003). Queens versus workers: sex-ratio conflict in the eusocial Hymenoptera. Trends Ecol Evol 18: 88-93.

Morel L, Vander Meer RK, Lofgren CS (1990). Comparison of nestmate recognition between monogyne and polygyne populations of Solenopsis invicta (Hymenoptera: Formicidae). Ann Ent Soc Am 83: 642-647.

Myles TG, Nutting WL (1988). Termite eusocial Evolution: a re-examination of Bartz's hypothesis and assumptions. $Q$ Rev Biol 63: 1-23.

Neigel JE (1997). A comparison of alternative strategies for estimating gene flow from genetic markers. Ann Rev Ecol Syst 28: 105-128.

Pamilo P, Gertsch P, Thorén P, Seppä P (1997). Molecular population genetics of social insects. Ann Rev Ecol Systematics 28: 1-25.

Pirk CWW, Neumann P, Moritz RFA, Pamilo P (2001). Intranest relatedness and nestmate recognition in the meadow ant Formica pratensis (R.). Behav Ecol Sociobiol 49: 366-374.

Queller DC, Goodnight KF (1989). Estimating relatedness using genetic markers. Evolution 43: 258-275.

Raymond M, Rousset F (1996). Genepop on the web. Available from http://wbjomed.curtin.edu.au/genepop/history.html

Reilly LM (1987). Measurements of inbreeding and average relatedness in a termite population. Am Nat 130: 339-349.

Roisin Y (1993). Selective pressures on pleometrosis and secondary polygyny: a comparison of termites and ants. In: Keller L (ed) Queen Number and Sociality in Insects. Oxford University Press: New York, pp 402-421.

Ross KG (1993). The breeding system of the fire ant Solenopsis invicta: effects on colony genetic structure. Am Nat 141: 554-576.
Ross KG (2001). Molecular ecology of social behaviour: analyses of breeding systems and genetic structure. Mol Ecol 10: 265-284.

Schmid-Hempel P, Crozier RH (1999). Polyandry versus polygyny versus parasites. Phil Trans Roy Soc Lond B 354: 507-515.

Sundström L, Boomsma JJ (2001). Conflicts and alliances in insect families. Heredity 86: 515-521.

Thompson GJ, Hebert PDN (1998). Population genetic structure of the Neotropical termite Nasutitermes nigriceps (Isoptera: Termitidae). Heredity 80: 48-55.

Thorne BL, Traniello JFA, Adams ES, Bulmer MS (1999). Reproductive dynamics and colony structure of subterranean termites of the genus Reticulitermes (Isoptera Rhinotermitidae): a review of the evidence from behavioral, ecological, and genetic studies. Ethol Ecol Evol 11: 149-169.

Trivers RL, Hare H (1976). Haplodiploidy and the evolution of the social insects. Science 191: 249-263.

Tsutsui ND, Suarez AV, Grosberg RK (2003). Genetic diversity, asymmetrical aggression, and recognition in a widespread invasive species. Proc Natl Acad Sci USA 100: 1078-1083.

Uva P, Clément J-L, Bagnères A-G (2004). Colonial and geographical variations in agonistic behaviour, cuticular hydrocarbons and mtDNA of Italian populations of Reticulitermes lucifugus (Isoptera, Rhinotermitidae). Insect Soc 51: 163-170.

Vargo EL (2000). Polymorphism at trinucleotide microsatellite loci in the subterranean termite Reticulitermes flavipes. Mol Ecol 9: 817-829.

Vargo EL (2003a). Genetic structure of Reticulitermes flavipes and $R$. virginicus (Isoptera: Rhinotermitidae) colonies in an urban habitat and tracking of colonies following treatment with hexaflumuron bait. Environ Entomol 32: 12711282.

Vargo EL (2003b). Hierarchical analysis of colony and population genetic structure in the eastern subterranean termite, Reticulitermes flavipes, using two classes of molecular markers. Evolution 57: 2805-2818.

Weir BS (1996). Genetic Data Analysis II. Sinauer Associates, Inc. Sunderland, MA.

Weir BS, Cockerham CC (1984). Estimating F-statistics for the analysis of population structure. Evolution 38: 1358-1370. 